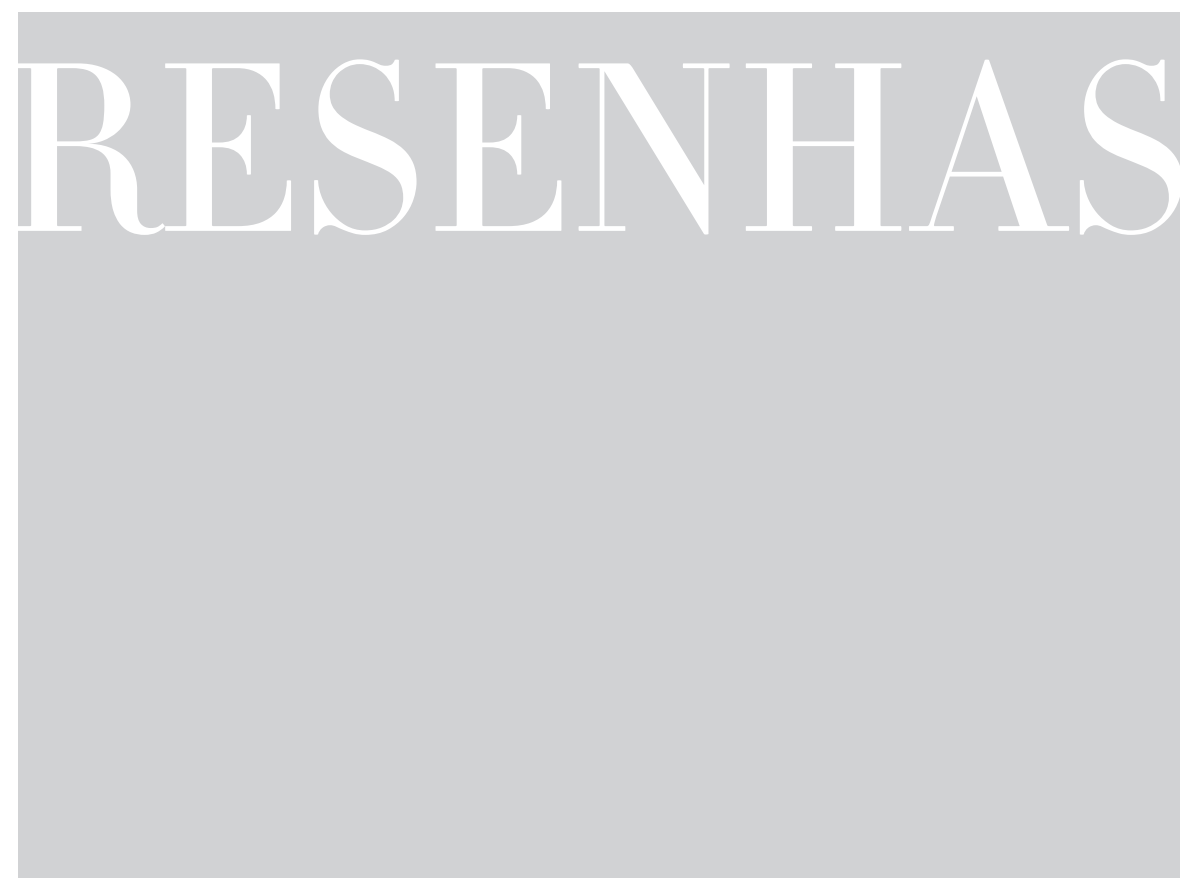

\title{
DISCURSO E ANÁLISE DO DISCURSO: (PARA ALÉM DE) UMA INTRODUÇÃO
}

No livro Discours et analyse du discours: introduction [Discurso e análise do discurso: introdução], Dominique Maingueneau, professor da Université Paris-Sorbonne (Paris IV), apresenta um estudo que contempla, de forma geral, retomadas e discussões acerca das múltiplas concepções, conceitos e caminhos da disciplina que dá nome ao livro: a Análise do Discurso - AD. Os 15 capítulos que compõem esse trabalho, ainda sem tradução para o português, abarcam questões discursivas atuais, em torno de noções-chave estudadas atualmente nessa disciplina.

O livro está dividido em três partes. Na primeira, "Études de discours et analyse du discours" [Estudos de discurso e análise do discurso], Maingueneau mostra um panorama geral da disciplina abordada. O primeiro capítulo - "Quelques élements d'histoire” [Alguns elementos de história] - traz um breve histórico sobre os percursos da $\mathrm{AD}$, campo em que não se pode delegar um lugar de emergência preciso. Autores como E. Goffman, L. Wittgenstein, M. Foucault e M. Bakhtin tiveram papel importante, mas compreendem apenas uma parte desse imenso campo que é a $\mathrm{AD}$. O termo "análise do discurso" é atribuído ao estruturalista Z. S. Harris (1952), sendo que sua emergência como disciplina aconteceu nos anos 1960, embora não se apresentasse como um projeto unificado, 
pois seguia caminhos diversificados nos Estados Unidos e na França e agrupava, ao longo de seu percurso, categorias de outras disciplinas, como a da linguística do texto.

Foi na França que, para Maingueneau, a $\mathrm{AD}$ se desenvolveu de forma mais acentuada, desde as publicações da revista Langage, número 13, e do livro de Pêcheux, Análise automática do discurso, em 1969. No mesmo ano, Foucault publicou Arqueologia do saber. Essas e outras obras colocam a questão do discurso como ponto central de discussão, mas apresentam trabalhos bastante diferentes uns dos outros. Passado esse período, a $\mathrm{AD}$ tem se apropriado de conceitos correntes, como a pragmática, a teoria da enunciação da linguística textual, etc. Os estudos atuais de autores como Charaudeau e Sophie Moirrand destacam o papel central do gênero do discurso, ancorando-se em uma teoria da enunciação, enquanto trabalhos como o de Kerbrat-Oreccioni, de perspectiva norte-americana, ganham espaço em pesquisas diversas.

Pelo histórico, é possível perceber a instabilidade do campo da $\mathrm{AD}$ desde sua emancipação como disciplina. O termo “discurso”, que dá nome à teoria, também não é uma noção estável, conforme assevera Maingueneau em "La notion de discours" [A noção de discurso], segundo capítulo do livro. Concebido como "uso da língua” para os linguistas, o termo tem significados diferentes ao se opor entre: discurso e frase, unidade transfrástica; discurso e língua, concebida como sistema e seu uso em contexto e discurso e texto, que o autor especificará no capítulo seguinte. O termo discurso é então concebido de maneiras amplas e difusas, podendo ser entendido como: organização para além da frase, uma forma de ação, interativo, contextualizado, ancorado por um sujeito, regido por normas, tomado em um interdiscurso, construtor social de sentido. Para o autor, toda problemática discursiva associa língua, atividade comunicacional e conhecimento. Esse agrupamento permite à $\mathrm{AD}$ se distinguir de outras disciplinas, que privilegiam normalmente uma dessas dimensões. O trabalho do analista não é, portanto, muito confortável, pois deve fazer um esforço constante para não se ater apenas ao linguístico. Esse desconforto evoca, e talvez justifique, o motivo de a presença da filosofia e de autores filósofos ser tão forte nesse campo.

Em “Discours, texte, corpus" [Discurso, texto e corpus], Maingueneau retoma a questão da relação existente entre discurso e texto, que pode designar tanto um único texto (que corresponde a um discurso) quanto um conjunto de textos (discursos que existem para além dos textos que os constituem). Os usos do termo texto também são amplos e podem ser considerados em três grandes pilares principais: texto-estrutura, texto-produto e texto-arquivo. Já a construção do corpus corresponde justamente ao agrupamento de textos, ou excertos de textos, que auxiliam os analistas a responder aos questionamentos levantados em suas pesquisas. Plural desde sua concepção como disciplina, a diversidade do 
campo de análise do discurso e suas inúmeras definições são abordadas em "Les disciplines du discours" [As disciplinas do discurso]. Para o autor, essa pluralidade depende das concepções teóricas adotadas pelos analistas, que podem optar por abordagens metodológicas ou por métodos situados entre os estudos do discurso e/ou a análise do discurso. Para Maingueneau, a $\mathrm{AD}$ deve ser considerada uma disciplina, não um método, já que seu interesse recai especificamente sobre as estruturas e suas relações sociais, além do uso da linguagem tal como acontece nos campos da sociolinguística, da retórica, etc. Em "Une analyse critique" [Uma análise crítica], o autor observa que os estudos dos discursos possuem atualmente duas vertentes: uma que analisa o funcionamento do discurso, voltando-se mais para os mecanismos da linguagem contidos dentro do próprio discurso, sem focar nas questões sociais propriamente ditas; e outra que se desenvolveu a partir dos anos 1990, mais ligada ao social e a ideologias circulantes, encaixando-se numa paisagem intelectual política de igualdade social, ideologias, poder e desigualdade - a análise crítica do discurso - ACD.

Perpassado esse primeiro momento de introdução e de explanação do quadro teórico-disciplinar da $\mathrm{AD}$, na segunda parte do livro, intitulada “Les unités de l'analyse du discours” [As unidades da análise do discurso], Maingueneau debruça-se sobre algumas unidades de análise que ele tem desenvolvido em sua trajetória de pesquisa e de publicações nos últimos anos. No sexto capítulo, “Les unités topiques” [As unidades tópicas], o autor amplia sua reflexão sobre as unidades tópicas, predeterminadas pelas práticas sociais, e as unidades não tópicas, definidas pelo pesquisador. Essas unidades são problematizadas em relação ao gênero, podendo ser agrupadas de acordo com a esfera da atividade, o campo discursivo e o lugar da sua atividade. Gênero, neste caso, é abordado em relação à sua circulação e força que possui para criar novos gêneros. Trata-se do princípio da valência genérica, uma metáfora da proposta de Tesnière ao princípio da centralidade do verbo, que passa a ser considerado por Maingueneau o princípio da centralidade do gênero. Essa valência pode ser: uma valência interna, que representa um conjunto de textos produzidos a partir do que se considera o núcleo e as produções de "avatares" prescritos (acordados), previsíveis (esperados), ou não esperados; e uma valência externa, que está relacionada à força do núcleo genérico de produzir a partir de si diferentes gêneros. Essa irradiação, hoje, assim como a produção de avatares, é facilitada pelo uso de novas tecnologias e também da internet.

Em "Les formations discursives" [As formações discursivas], Maingueneau aborda a estabilidade da noção de formação discursiva, conceito polêmico e de "dupla paternidade" (Pêcheux e Foucault), discutindo questões relacionadas às formações discursivas de identidade, reunidas a partir da instância de produção, as formações discursivas 
temáticas, cuja organização parte de um tema, os temas-chave e temas pré-construídos, como formas de arranjo, e as formações discursivas plurifocais. A formação discursiva, como concebida tradicionalmente, é bastante ampla e intenta integrar os textos em um conjunto muito vasto, em torno de um campo ou vários. Em "Parcours et registre” [Percurso e registro], o autor prefere falar em percursos e registros para análise de uma circulação, uma dispersão de materiais heterogêneos que se constroem em torno de um significante muito variável, como o caso das análises das fórmulas discursivas (trabalhos de Krieg-Planque) e as pequenas frases (trabalhos de Maingueneau), unidades não tópicas de análise reunidas pelo pesquisador a partir de um princípio de coerência que se justifica pelos objetivos da pesquisa.

Na terceira parte do livro, "L'univers du discours" [O universo do discurso], Maingueneau se aprofunda nas questões discursivas da $\mathrm{AD}$, elencando e discutindo alguns pontos específicos em torno desse universo. Ele inicia com "Unité et diversité” [Unidade e diversidade], em que discorre sobre os gêneros do discurso e aborda questões autorais, rotineiras e da conversação. Maingueneau adverte que a análise do discurso deve mobilizar aparelhos conceituais e metodológicos específicos para estudar as práticas de atividades verbais integradas ao desempenho de atividades não verbais. Ainda em relação à genericidade, em “Genre de discours et scène d'énonciation" [Gênero do discurso e cena da enunciação], o autor retoma a noção de gênero para problematizar a interação de três cenas distintas: a cena englobante, a cena genérica e a cenografia. Esse esquema permite Maingueneau abordar a noção de hipergênero como uma formatação (modos de apresentação) que abarca diversos gêneros.

Em “Énonciation attachée et énonciation détachée" [Enunciação ligada e enunciação destacada], é retomada a noção de enunciação aforizante, distinguida em dois tipos principais: as autônomas (slogans, adágios, provérbios, etc.); e as que compõem partes de um texto (citações famosas ou partes de uma notícia de jornal). Nessa retomada o autor posiciona-se em relação à sua opção de tratar enunciados como frases sem texto e propõe-se a aproximar essa categoria de aforização à de autor, que para ele não costuma designar nem o enunciador nem um indivíduo de carne e osso, mas sim uma função. Designado como auctor (étimo latino de autor), para Maingueneau há uma forte ressonância dessa função com a figura do aforizador, já que, quando há obra (agrupamento de textos atribuídos a um auctor), o gênero é relegado a segundo plano e as aforizações permitem que essas obras passem a compor novos estatutos pragmáticos.

No capítulo "L'espace du discours" [O espaço do discurso], o autor se questiona sobre o estatuto paradoxal dos discursos constituintes, abordando a noção de paratopia como pertença, manifesta em dois níveis 
complementares: ao nível do discurso constituinte (discursos religiosos, filosóficos, científicos, etc.); e ao nível de cada produtor de texto relevante de um discurso constituinte, em que o falante deve gerir uma impossível identidade por meio das formas de pertença e não pertença da sociedade. Por não ser uma zona de produção homogênea, os discursos constituintes não podem ser tratados hierarquicamente como se faz com os gêneros do discurso, pois eles gestionam as práticas discursivas que o estruturam. No capítulo seguinte, "Le discours et ses traces" [O discurso e seus traços], Maingueneau se atém aos traços da enunciação para tratar de enunciados que se conservam e são passíveis de serem transformados em objetos de futuras retomadas e de novos tratamentos. O arquivamento desses traços tem se difundido de forma muito crescente, principalmente com o surgimento da internet. O problema, segundo o autor, não está mais em como organizar todo esse arquivo, mas sim em definir critérios do que é relevante ser arquivado para o futuro, uma tarefa difícil e nada exata.

A partir da constatação de que, juntamente com o desenvolvimento da tecnologia, surgiram novas práticas específicas do universo digital, em "Nouvelles textualités” [Novas textualidades], Maingueneau afirma que há hoje uma profunda mudança no que se refere às modalidades tradicionais do discurso. A primeira pode ser observada em relação à multimodalidade, comunicação que mobiliza diferentes canais. Isso se complica quando enunciados escritos passaram a abranger elementos icônicos, o que permite falar hoje em iconotextos para designar produções semióticas que mesclam os usos de imagem e de palavra. A partir da observação de que há um desnivelamento entre as cenografias que circulam em páginas da web, Maingueneau distingue dois tipos de cenografias recorrentes em sites: uma cenografia verbal, que implica a enunciação (a elaboração de um gênero); e uma cenografia digital, que corresponde à enunciação inserida na web (quando os gêneros são incluídos na web). Essa cenografia digital resulta da interação de três componentes (convergentes ou divergentes): iconotextual, arquitetônico e procedural. Para o autor, cada tipo de comunicação (oral, impressa e digital) acarreta formas de textualidades distintas: uma emergente, da oralidade conversacional; outra planificada, dos gêneros instituídos que se manifestam de forma monologal ou dialogal; e outra navegante, que implica uma transformação da noção de leitura, uma vez que cada leitor pode construir seu próprio hipergênero a partir das escolhas e dos caminhos que escolhe durante sua navegação.

No último capítulo do livro, “Communication d'un troisième type” [Comunicação de um terceiro tipo], Maingueneau discute a representação das atividades verbais em relação à evolução das novas tecnologias da comunicação, que envolvem as duas formas de textualidades orgânicas - tanto aspectos escritos quanto orais - e problematizam o 
que se entende normalmente por destinatário. Para Maingueneau, as novas situações, como as postagens, os tweets, etc., fundem constantemente as três formas de textualidades e de genericidades tradadas no capítulo anterior. Outra problemática referente às novas tecnologias e à circulação na web está relacionada com o surgimento de um "locutor angelical”, que existe apenas como o correlato de uma enunciação e é atribuído a indivíduos que não são propriamente os sujeitos falantes.

Embora se proponha como uma introdução, o livro de Maingueneau aborda de forma bastante ampla questões relativas aos estudos do discurso e da análise do discurso, mesmo que focado em problemáticas discursivas desenvolvidas pelo próprio autor ao longo de sua trajetória. Essa amplitude, de certa forma, vai na contramão de obras com caráter introdutório. Além de apresentar um percurso histórico, o autor sugere caminhos possíveis e expande algumas de suas teorias e conceitos, abarcando problemáticas discursivas bastante atuais, o que tem sido, de certa forma, uma marca de seu percurso no campo da AD. Por esse motivo, acreditamos que a leitura do livro pode ser interessante para alunos e pesquisadores das diversas áreas que se utilizam do discurso como objeto de análise.

\section{ANDRÉ WILLIAM ALVES DE ASSIS}

Doutorando em Linguística pela Universidade Federal de Minas Gerais - UFMG -, Belo Horizonte, Minas Gerais, Brasil

assis.awa@gmail.com

\section{RAQUEL TIEMI MASUDA MARECO}

Doutoranda em Letras pela Universidade Estadual de Maringá - UEM -, Maringá, Paraná, Brasil

rachel.mareco@gmail.com

\section{TATIANA EMEDIATO CORRÊA}

Mestranda em Linguística pela Universidade Federal de Minas Gerais - UFMG -, Belo Horizonte, Minas Gerais, Brasil

tatyemedcorrea@gmail.com 